\title{
MOVILIDAD SOCIAL en Ciudad Juárez
}

RAMÓN MORENO

\section{RESUMEN}

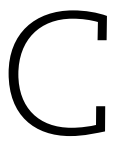

iudad Juárez es una localidad del norte de México cuya estructura social, cultural, demográfica, urbana, económica, geográfica y territorial se ha visto sacudida por diversos vaivenes que le han impuesto diversas etiquetas, una de ellas es la de ser considerada como una localidad violenta e insegura, partiendo de las condiciones de inseguridad que brotaron en ella a partir de 2008.

A partir de esta reflexión surge el interés de conocer y estudiar los procesos relacionados con los residentes que han habitado la ciudad en diversos momentos y, como ellos, han presentado distintos movimientos en su habitar cotidiano acudiendo a dos vertientes principales: primero, observar aquellos procesos socioespaciales en una localidad fronteriza del norte de México, ocurridos en tiempos distintos, donde se obtiene una visión integral de su historia, cultura, sociedad, economía y urbanización y su relación con los hechos que han intervenido en la construcción de un medio social específico; y segundo, observar las experiencias de sus residentes al adquirir un estatus de propietario de su vivienda y con ello fotografiar el proceso de movilidad social que adquirió durante su vida.

La metodología a utilizar en este estudio parte de un análisis socioespacial considerando como punto de partida los conceptos de movilidad social y entorno construido para de allí reflexionar 
sobre alternativas que tienen algunos lugares en Ciudad Juárez de ser revitalizados. Se incluyen resultados de los cuestionarios aplicados en diversas colonias y fraccionamientos, así como la cartografía, fotografía y entrevistas.

Palabras clave: movilización social, entorno construido, espacio público.

\section{INTRODUCCIÓN}

El territorio urbano es un elemento que incluye factores geográficos, sociológicos, urbanísticos, económicos, políticos, ideológicos, culturales, jurídicos, históricos y arquitectónicos que permiten describir las formas y mecanismos que realiza el hombre al interior de su espacio físico, el cual se ve influenciado por las condiciones que la naturaleza le impone ahí donde convergen distintas expresiones para entender las acciones humanas en su modificación y transformación. Por otro lado, las prácticas individuales o colectivas de los seres humanos coadyuvan a dar un sentido distinto a aquel lugar que pretende modificar, dependiendo directamente de los objetivos que se persigan.

Así, se resaltan tres elementos fundamentales en el análisis de la integración de territorio y sociedad: movilidad social, como aquel proceso que permite al individuo mejorar sus condiciones de vida y por ello crear nuevas posibilidades de ascender en la jerarquía social; entorno construido, el lugar que permite al ser humano adaptarse para mejorar o no su vida. En este se pueden citar vivienda, escuela, familia, trabajo y vecinos como parte fundamental en la creación de nuevas interacciones individuales y colectivas que le permiten dar un sentido práctico y complementario a sus necesidades fundamentales; el espacio público, representado por plazas, parques, avenidas y calles, permite dar una orientación al individuo en cuanto a mecanismos de transitar, percibir y visualizar, entre otros elementos que ayudan a entender esos procesos de adaptación e integración social que se ejerce por parte de la persona cuando pretende resolver algunas necesidades básicas. 
Un elemento que se integra a esta reflexión es la siguiente pregunta de investigación: ¿Cómo influye la movilidad social en la construcción socioespacial y sus mecanismos en la relación con el entorno y el espacio público de Ciudad Juárez? A partir de los diversos contextos que adquiere el residente propietario de vivienda de interés social y cómo estos se vinculan en el medio físico donde se han establecido.

El contenido de este trabajo se orienta en la primera parte a realizar un sustento teórico que permita explicar los conceptos claves de este estudio: movilidad social, entorno construido y espacio público. En la segunda parte, el marco contextual donde se hace referencia a los procesos espaciales que vinculad la sociedad y el territorio de Ciudad Juárez. Y en un tercer momento, la vinculación de los elementos de análisis citados en este estudio a través de cartografía y resultados de herramientas metodológicas como el cuestionario y entrevistas.

\section{PRIMER NIVEL DE ANÁLISIS: REFLEXIÓN TEÓRICA DE LA MOVILIDAD SOCIAL, ENTORNO CONSTRUIDO Y ESPACIO PÚBLICO}

A partir de la pregunta: ¿Cómo influye la movilidad social en la construcción socioespacial y sus mecanismos en la relación con el entorno y el espacio público de Ciudad Juárez?, en esta sección se abordan los elementos claves: movilidad social, entorno construido y espacio público como una relación conceptual en dos apartados relacionales: el primero, definiendo la movilidad social como parte del cambio que adquieren los individuos al vivir en una determinada zona urbana, y el segundo, integrando las aportaciones al entorno construido y espacio público como indicadores significativos de estos desplazamientos o movimientos que realizan los residentes de una ciudad para analizar sus comportamientos en una escala de ascenso o descenso a nivel económico, urbano o social que les permita mejorar sus condiciones de vida.

Así entonces, incluyendo la definición que realiza el Centro de Estudios Espinoza Yglesias (2013), en donde dice que la movilidad 
social es la facilidad con la que los miembros de una sociedad cambian de nivel socioeconómico, se aprecia en ella una discrepancia en la forma de caracterizar este tipo de procesos, que no solamente es una decisión rápida y sobre todo fácil; la movilidad implica toda una serie de actividades personales y colectivas que tienen que ver con el bienestar tanto de la persona como del grupo; por tanto, es importante considerar, en este concepto, que implica distintas manifestaciones de cambio.

Precisamente estas manifestaciones de cambio son las que permiten identificar distintas trayectorias de los habitantes que habitan una ciudad determinada y aún más, si esta se localiza en la zona fronteriza del norte de México, particularmente interesa resaltar que de acuerdo al informe citado la movilidad social es un elemento que destaca la condición de tipo económico del grupo atendiendo su condición de bienestar y pobreza, el objetivo de este trabajo es visualizar las condiciones a nivel social y espacial que se gestan al interior del grupo partiendo de la premisa de entender al sujeto como ser social y que busca ante todo una mejoría significativa al interior de su familia y entorno, a través de edificar su mundo social, cuando este decide dejar el seno paterno y crear el suyo propio.

Así entonces un primer retrato de la movilidad social es caracterizar los ejes conductores que mueven al individuo a buscar este ascenso o descenso en algunos casos. Para ello, y de acuerdo con Chávez Molina (2013: 2), este tema se ubica en el contexto como una mirada distributiva; la desigualdad no solo como un efecto procedimental, sino además como el patrón de acceso a oportunidades que implican resultados disímiles en la vida de las personas. Y desde esa perspectiva analítica, considerar las probables oportunidades no tan solo de mejores condiciones de vida a lo largo de un trayecto personal o intergeneracional de los individuos.

Por otro lado, el espacio que identifican los residentes depende en gran medida del tipo de vivienda y el lugar en que esta se encuentre para determinar los elementos que identifiquen claramente la percepción que tengan respecto al desplazamiento que hagan considerando el punto inicial (hogar de sus padres) al centro de destino (vivienda propia y en particular con la construcción 
de su familia: esposa [o] e hijos). Así, en este desplazamiento se puede identificar cada hecho en particular que haga a los habitantes construir percepciones distintas. La movilidad en estas reflexiones permite vislumbrar ejes de interacción que puedan marcar características singulares en el espacio donde deciden habitar.

Por otra parte, la movilidad social, de acuerdo con Giddens (2009: 498), se refiere al movimiento de los individuos y grupos entre las distintas posiciones económicas. Además, señala dos tipos principales dentro de esta categoría: la movilidad vertical, que es un desplazamiento hacia arriba o hacia abajo en la escala socioeconómica, y la de tipo horizontal, que hace referencia a la traslación de un barrio a otro o entre ciudades y regiones. Estas cualidades permiten visualizar los procedimientos que asumen los individuos y grupos cuando se ven en la necesidad de desplazarse, ya sea a nivel vertical u horizontal, en un territorio específico, para medir la composición social del individuo y del grupo que habita en una ciudad determinada.

El mismo Giddens (2009: 499) asume que la movilidad vertical en una sociedad es un nivel de "apertura" que señala hasta qué punto un individuo con capacidad nacido en un estrato inferior puede ascender en la escala socioeconómica; dos categorías más son analizadas por este autor para comprender el proceso de movimiento que tienen los individuos en la sociedad: la intrageneracional, relacionada directamente con el grado de escolaridad, y la intergeneracional, que se efectúa en algunas cualidades entre hijos, padres y abuelos.

El segundo aspecto, que relaciona movilidad social con espacio público y entorno construido, son las aportaciones que realizan algunos expertos sobre la importancia que tienen estos (el medio construido y el espacio público), con las interacciones cotidianas que realizan los individuos, sobre todo aquellos que han adquirido una vivienda propia o se han cambiado del hogar tradicional que habitaron con sus padres o abuelos.

En este sentido, Brenna (2012: 84) argumenta que el espacio contiene una red nerviosa constituida por los recorridos, las trayectorias, los itinerarios y las redes, lo que lo convierte en un elemento de enorme plasticidad, pero también en un instrumento 
de mediación entre grupos, individuos y topos diferentemente situados. Por otro lado, Rodríguez (2011: 65) expresa el doble carácter que asume el concepto de espacio público, desde el punto de vista físico que ordena e integra la ciudad y lo público, social y cultural donde se condensan la vida urbana, los valores, gustos y costumbres de un pueblo.

Complementando algunas reflexiones de Brenna y Rodríguez, se une a la de ellos la postura propuesta por Campos (2012: 162) al afirmar que el espacio público es aquel espacio físico socialmente conformado, accesible a todos como área de encuentro social que implica una copresencia entre desconocidos y que es susceptible de distintos usos, en la que el encuentro se efectúa como parte de la experiencia cotidiana. En estos términos coincide con Fuentes y Peña (2011:49) al afirmar que el uso del espacio público está condicionado por las diferencias socioespaciales que se explican en gran medida por los procesos sociales y económicos en los que se construye la ciudad. Aquí, entonces, se resaltan el rol fundamental que concierne a los grupos, el territorio y los mecanismos que se utilizan para identificar elementos simbólicos, sociales, históricos, de experiencias en el habitar de la ciudad y sobre todo las condiciones imperantes en el medio físico donde se establecen los grupos humanos.

Lo anterior nos permite rescatar la definición que realiza Maycotte (2011: 188) al afirmar que el espacio público, además de contener los símbolos y valores culturales de un grupo social, también asume cualidades de carácter espacial y territorial, cuya importancia estriba en su capacidad de impactar no solo en las condiciones, sino también en la calidad de vida de sus potenciales usuarios, reflexión que es compartida por Rodríguez (2011: 69) cuando afirma la importancia de los subcentros asociados con las nuevas áreas de expansión y crecimiento de la ciudad.

La relación de la movilidad social que surge en el ámbito urbano en una localidad fronteriza del norte de México, permite visualizar hechos sociales y culturales que se concretan en un espacio público y en un entorno que se ha construido para mejorar las condiciones de vida propuestas por sus residentes. En esta dirección, entonces, el espacio público juega un papel preponde- 
rante en esta construcción de redes sociales dentro de la colonia o fraccionamiento donde se eligió vivir. El lugar influye en si este desplazamiento va en sentido ascendente o descendente, como lo explica Giddens (2009: 501). La movilidad descendente se da menos que la ascendente, lo cual no deja de ser un fenómeno generalizado. La movilidad intergeneracional descendente es también habitual, y se relaciona con ansiedades y problemas psicológicos. Por su parte, Campos (2012: 179) considera que el espacio es una construcción social que convoca y requiere la heterogeneidad social; el eje articulador entre el espacio y la sociedad son las relaciones y los vínculos que las personas establecen a partir de la apropiación, sea esta por transformación o identificación.

En este sentido, la movilidad social que interesa destacar en este estudio, si bien es cierto procura destacar factores económicos, se orienta a entender los elementos socioculturales que se presentan en torno a la vivienda y sus connotaciones intergeneracionales que suceden en el momento del cambio de residencia. En este sentido, Módenes (2006: 5) establece que una de las formas de entender este proceso es asumir su interdependencia y considerar cómo los individuos combinan diferentes comportamientos de movilidad para cumplir sus fines a corto y largo plazo. Esta visión sistémica de la movilidad espacial asume la interdependencia entre movilidades, que puede tomar la forma de complementariedad, compensación o sustitución. De acuerdo con lo anterior, la tipología que interesa destacar en el caso de Ciudad Juárez es: a) la movilidad social que se genera a principios de su fundación; b) aquella que se presenta en el proceso de crecimiento y desarrollo y que comúnmente se asocia con la descrita por Giddens, de tipo generacional; c) la que ocurre durante el proceso de expansión urbana (Campos, Fuentes, Maycotte y Módenes); y d) aquella que se relaciona con la selección de vivienda como parte de la oferta y demanda de vivienda. 


\section{SEGUNDO NIVEL DE ANÁLISIS: MARCO CONTEXTUAL DE LA MOVILIDAD SOCIAL EN CIUDAD JUÁREZ}

La antigua Paso del Norte, nombre con el que se le conoció inicialmente a esta ciudad, forma parte de un conjunto de procesos históricos, sociales, culturales, demográficos, económicos y políticos que le han bastado para cambiar en su estructura urbana en forma específica, el espacio humano que en ella se ha configurado ha creado diversos polos de desarrollo que al interior de ella se pueden mostrar en su territorio: un paisaje lleno de contrastes, entre los que se encuentran barrios, colonias y algunos fraccionamientos fundacionales, pasando por una etapa expansiva de crecimiento hacia el Norte y Sur y llegando a una fase expansiva significativa hacia el Poniente, Oriente y Sur con distintos asentamientos y grupos humanos que a ellos llegaron.

Esta clasificación permite identificar los procesos urbanos relacionados con nuestros conceptos claves, como lo son movilidad social, entorno construido y espacio público como mecanismos de entender lo que sucede a nivel socioespacial en Ciudad Juárez. Un primer acercamiento a ello lo constituye el mapa 1, en donde se ubica el crecimiento histórico de la mancha urbana de Ciudad Juárez, Chihuahua. Así, en este sentido, otros periodos de crecimiento urbano en Juárez van a marcar fuertemente la composición de los grupos dentro de su estructura; cada uno, como se ejemplifica en esta cartografía de expansión de la ciudad, permite ubicar desde 1911 hasta 1960 un crecimiento lineal en cuanto a los procesos económicos, de desarrollo urbano y demográficos. Los asentamientos se van extendiendo progresivamente a través del territorio de Juárez en forma desordenada, lo que se incrementa en forma irregular en los años sesenta y parte de los setenta. 
Mapa 1. Crecimiento histórico de la mancha urbana en Ciudad Juárez

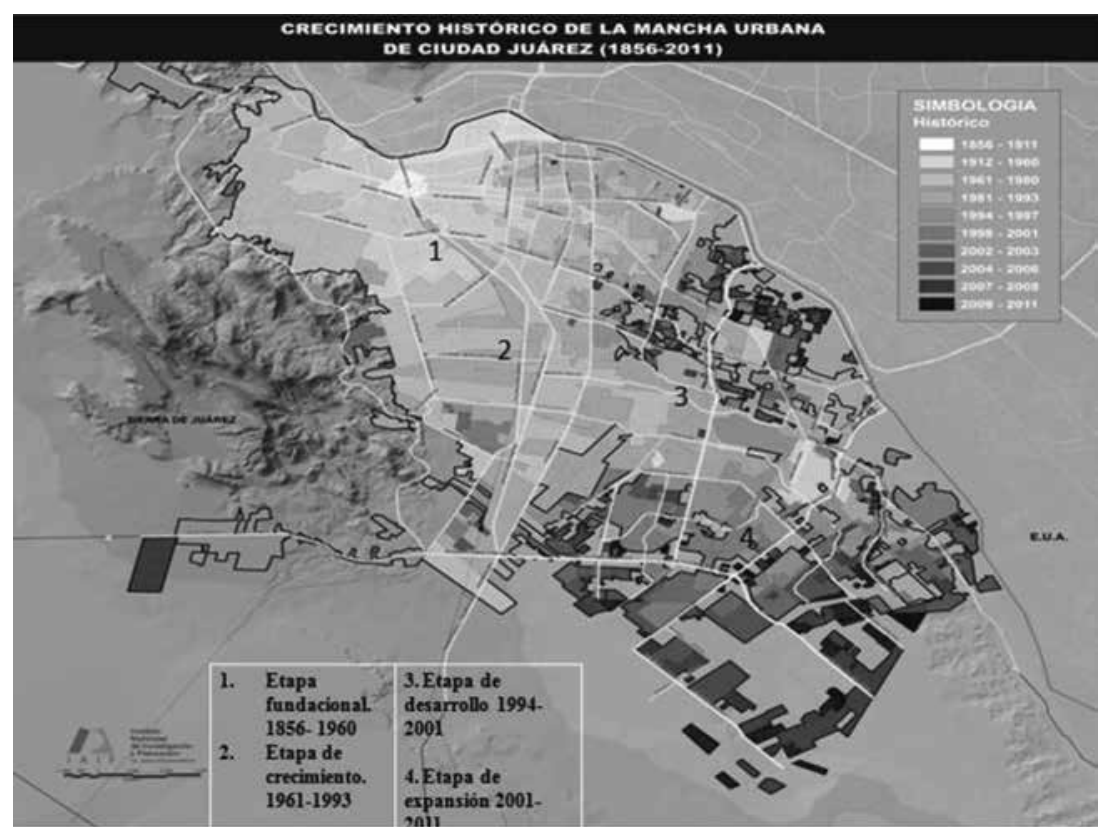

Fuente: Instituto Municipal de Investigación y Planeación (2011). Plan de desarrollo urbano de Ciudad Juárez. Ayuntamiento de Ciudad Juárez.

Durante los posteriores años que se ilustran en el mapa 1 se construye un acercamiento al tipo de movilidad social que se ha gestado en Ciudad Juárez, de tipo horizontal, referida al cambio de colonia, barrio o fraccionamiento; cada uno de ellos retrata esos primeros paisajes que se descubren en la realidad urbana de esta localidad de Chihuahua, mostradas en las etapas 1 y 2 en los periodos 1856-1960 y 1961-1993, ante el crecimiento urbano y expansión de colonias y fraccionamientos cuyos objetivos principales buscan ofertar distintas formas de vivienda en la ciudad, haciendo de ellos una fuente de ingreso económico fuerte en las constructoras inmobiliarias, con el sustento de brindar vivienda económica en la ciudad a los grupos de bajos ingresos.

Estas primeras formas de movilidad social van a asentarse en diferentes territorios de Ciudad Juárez, permitiendo identificar 
grupos de bajos y medios ingresos establecidos en el centro, norte y poniente de la ciudad (números 1 y 2 del mapa 1).

En las etapas 3 y 4, definidas como de desarrollo (1994-2001) y de expansión (2001-2011), la tipología de hacer ciudad se concentra en varios procesos: a) dispersión de la industria maquiladora; b) llegada de nuevos grupos humanos; c) aparición de nuevos espacios urbanos, como los fraccionamientos cerrados; y d) surgimiento de problemática social que no se había hecho presente en la ciudad, como la violencia y la inseguridad, lo que vino a modificar la vida cotidiana en la misma. Los patrones de construcción de vivienda se vinieron a diferenciar de manera significativa en las zonas del sur, oriente y norte de Juárez. El miedo ante la inseguridad que se hizo presente en colonias y fraccionamientos del sur y oriente indicaron manifestaciones de vulnerabilidad que hicieron también modificar los patrones de la movilidad social. Por ejemplo, en la fase 3 del mapa 1, se muestran cambios en cuanto a los desplazamientos poblacionales hacia las urbanizaciones cerradas, o bien, el regreso a sus lugares de origen, particularmente en la zona del centro y del poniente donde estaban los hogares paternos.

En relación con lo anterior, en la tabla 1 se agregan aquellos procesos específicos que resultan en cada una de estas fases de desarrollo en la ciudad con respecto a la movilidad social. Por un lado, la tipología en cuanto a la vivienda que se oferta en la ciudad es un factor importante en esta descripción de las cualidades que hacen los habitantes de su espacio y aquellos elementos de carácter físico que se entretejen en el espacio urbano y que se pueden observar durante las cuatro etapas del nacimiento, desarrollo y expansión urbana en Ciudad Juárez, donde las distintas áreas que se construyeron en ellas muestran diferencias significativas, sobre todo en el espacio público y el entorno social que se fue edificado en cada colonia, fraccionamiento o barrio que se establecieron en esas zonas. Tal y como es señalado por Giddens (2009), el proceso de movilidad social atiende principalmente a las características de la población y el lugar donde se establecen, como también ha expresado Campos (2012).

Los datos que se incluyen en la tabla 1 permiten visualizar cómo se han construido el espacio físico y el entorno social que se 
ha identificado por medio de las entrevistas y recorridos de campo en las distintas zonas de Ciudad Juárez. La movilidad social a la cual se hace referencia en esta información permite clasificar tipologías específicas para el caso de la etapa 1, el proceso fundacional, cuya cualidad básica es la referida al tipo horizontal, el desplazamiento de residentes de un lugar a otro o de una región, país o municipio foráneo. En este caso, para Juárez es significativo que los grupos se van estableciendo en los primeros barrios y colonias de la ciudad (sitios marcados con el número 1 del mapa 1). Por su parte, en la etapa 2, el cambio se deja sentir en el territorio de Ciudad Juárez. Los procesos de transformación de las actividades económicas, sobre todo de las de tipo primario (agrícolas) van a sufrir una modificación sustantiva en cuanto a su organización: aparecen industrias maquiladoras en su mayor expresión y ello trae como consecuencia empleos, llegada a la ciudad de nueva población y además la posibilidad de oferta de vivienda para estos residentes que llegaron a habitar Ciudad Juárez. La movilidad social horizontal se expande y la vertical tiene nuevas manifestaciones en cuanto a los ingresos y la expansión de distinta población económicamente activa, que es recibida en los sectores del norte, poniente y algunas zonas del sur y oriente.

Tabla 1. Relación de la movilidad social con el espacio urbano en Ciudad Juárez

\begin{tabular}{|c|c|c|}
\hline $\begin{array}{l}\text { 1. Etapa } \\
\text { fundacional } \\
1856-1960 \\
\end{array}$ & Movilidad social horizontal & Tipo intergeneracional \\
\hline $\begin{array}{l}\text { 2. Etapa de } \\
\text { crecimiento } \\
\text { 1961-1993 } \\
\end{array}$ & $\begin{array}{l}\text { Movilidad social horizontal } \\
\text { Surgimiento de la vertical } \\
\text { Movilidad vertical }\end{array}$ & $\begin{array}{l}\text { Combinación en los tipos de la } \\
\text { movilidad social }\end{array}$ \\
\hline $\begin{array}{l}\text { 3. Etapa de } \\
\text { desarrollo } \\
\text { 1994-2001 } \\
\end{array}$ & $\begin{array}{l}\text { Movilidad horizontal, sobre } \\
\text { todo con la aparición de vi- } \\
\text { viendas exclusivas }\end{array}$ & $\begin{array}{l}\text { Surgen nuevas cualidades en } \\
\text { los grupos que se asientan en } \\
\text { esta fase. Ascensos personales }\end{array}$ \\
\hline $\begin{array}{l}\text { 4. Etapa de } \\
\text { expansión } \\
\text { 2002-2011 }\end{array}$ & $\begin{array}{l}\text { Combinación en las tipolo- } \\
\text { gías de la movilidad social en } \\
\text { relación con los programas de } \\
\text { vivienda }\end{array}$ & $\begin{array}{l}\text { Zonas diferenciadas } \\
\text { Grupos heterogéneos }\end{array}$ \\
\hline
\end{tabular}

Fuente: Elaboración propia con base en trabajo de campo y observación cartográfica 
Las etapas 3 y 4 de la tabla 1 denotan dos grandes procesos en la edificación de la movilidad social en Ciudad Juárez, durante la etapa de 1994 al 2001. Atendiendo las cualidades de la población que no solamente se empleaba en la industria maquiladora, sino en el comercio y servicios, los ascensos en los empleos van a contribuir en la aparición de ascensos en algunos grupos en su estructura personal por medio de los ingresos. Además, la aparición de viviendas exclusivas forma parte de estos mosaicos de desplazamientos de los residentes, en particular a la zona de integración ecológica, que concentra en su mayoría fraccionamientos de este tipo, pero la zona suroriente se cobijaría de nuevos conjuntos habitacionales para población de ingresos bajos y medios.

La etapa 4, definida en el periodo 2002-2011, forma parte de un mosaico lleno de paisajes urbanos en Ciudad Juárez. La movilidad social horizontal sigue destacando en los grupos poblacionales que arriban a esta frontera, en la medida en que el empleo se expandía y la promoción de vivienda se integraba en los primeros años de este período. Ello hacía más compleja la movilidad de tipo vertical, sin embargo, esta tenía otros matices en las zonas que se desarrollaron durante esta fase.

Por ejemplo, las etapas recientes de crecimiento urbano, como la 3 y 4 , se han visto influenciadas por distintos procesos sociales que han impactado su propio habitar. Por ejemplo, en la zona 3 se marcan áreas provenientes de la inseguridad. Y en la 4, uno de los problemas fuertes que se tienen es el abandono de viviendas, seguido por la situación físico-ambiental donde se crearon las mismas. Aquí vale la pena comentar que es en estas zonas donde el espacio público necesita de revitalización, ya que son áreas totalmente desprotegidas por los ámbitos federal, estatal y municipal. Otro punto que se destaca es la zona 4, donde los programas de vivienda fueron impulsados con mayor frecuencia a partir del 2000, cuando se crearon condiciones para desarrollar distintas colonias y fraccionamientos en la parte sur y oriente de la ciudad (zonas 3 y 4). 


\section{ESCENARIOS DE LA MOVILIDAD SOCIAL Y EL ENTORNO CONSTRUIDO EN CIUDAD JUÁREZ}

En respuesta a las etapas descritas en el mapa 1 y en la tabla 1, los escenarios que se crearon en Ciudad Juárez responden también a otros hechos sociales que se manifestaron sobre todo en las etapas 3 y 4, producto de crisis económicas, abandono de vivienda, violencia e inseguridad, entre otras situaciones que se marcaron con emblemas: "la ciudad más violenta del mundo", "Juárez, el nido de los narcos", "las muertas de Juárez", entre otros estigmas que vinieron a darle otra imagen diferente y con lo que la relación entre movilidad social, entorno construido y espacio público respondería a esas circunstancias produciendo distintos escenarios en cuanto a habitar la ciudad.

En relación con lo anterior, como muestra de lo encontrado en recorridos de campo por selección aleatoria, se eligieron cuatro fotografías para ilustrar los escenarios construidos en Ciudad Juárez en las etapas que se describieron en el mapa 1 y la tabla 1.

La figura 1 se compone de dos fotografías; la señalada con la letra A corresponde a un prototipo de vivienda que se construyó en las primeras etapas fundacionales de Ciudad Juárez, sobre todo en colonias populares como La Chaveña, Barrio Alto, Hidalgo y Margaritas, ubicadas en el entorno número 1 del mapa 1. La vivienda en estas áreas tiene un significado importante en la medida que los habitantes asumieron sus condiciones de propietarios. La imagen B de esta figura corresponde a un parque en la zona poniente de la ciudad, edificado en un territorio agreste, difícil sobre todo porque la recreación se vuelve compleja para sus habitantes. Sin embargo, para los habitantes de las colonias aledañas al sitio, es un centro importante de convivencia. 
Figura 1. Contexto urbano de Ciudad Juárez en las etapas 1 y 2
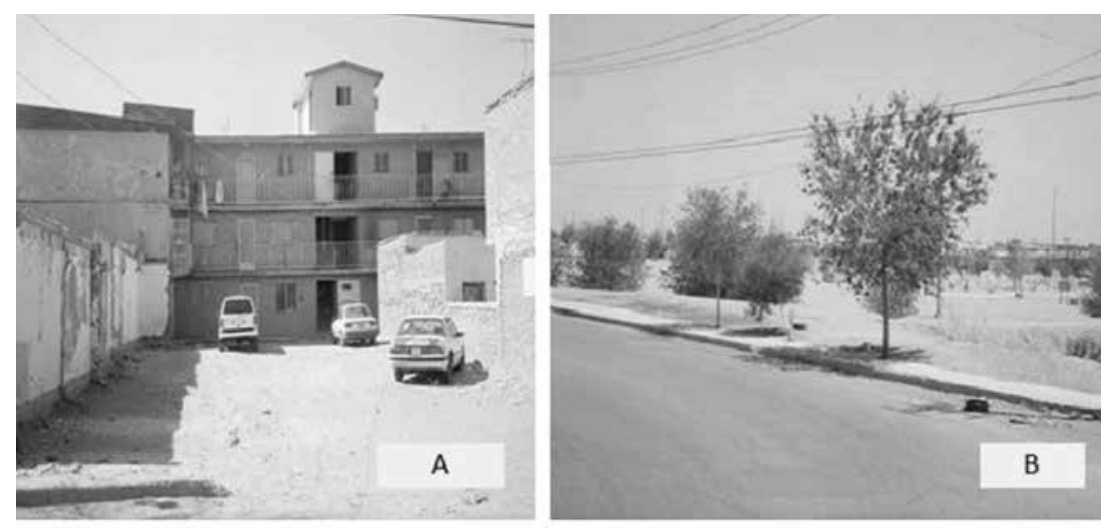

Fuente: Ramón L. Moreno M. (2011). Recorrido de campo

En cuanto a la figura 2, el desarrollo urbano en la ciudad muestra otros hechos significativos que se relacionan con la construcción de un espacio defensivo y sobre todo con la necesidad de protección ante la inseguridad que se vive en Juárez como resultado de los incrementos en actos delictivos y vandálicos. En la foto $C$ se muestra un ejemplo de la organización de los vecinos por medio de la apropiación del espacio público, el cierre de calles, y en el caso de la imagen $\mathrm{D}$, un conjunto habitacional del oriente de la ciudad, en su mayor parte en situación de abandono. Este fraccionamiento se proponía como objetivo central impulsar la vivienda económica para grupos de ingresos bajos y un punto para impulsar la movilidad social de los mismos, pero debido a la crisis económica y la inseguridad que imperó sobre todo a finales del 2008 y continuando hasta el 2012, muchas casas fueron abandonadas. 
Figura 2. Contexto urbano de Ciudad Juárez en las etapas 3 y 4
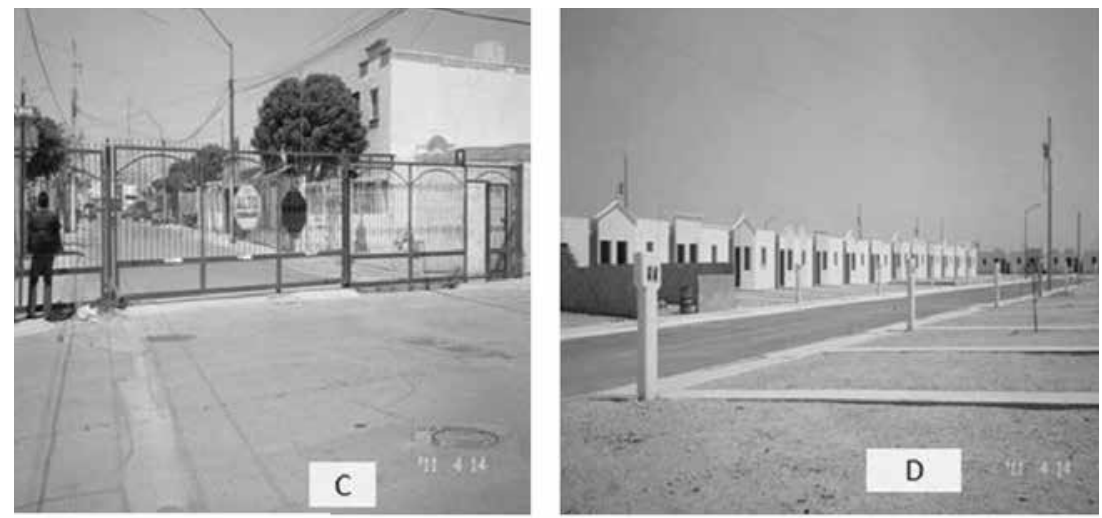

Fuente: Ramón L. Moreno M. (2011). Recorrido de campo

Los microespacios que se ilustran en las fotos A (vivienda), B (espacio público), C (entorno apropiado) y D (conjuntos habitacionales semiocupados y abandonados) en las distintas etapas descritas anteriormente, se explica la transformación que han tenido a través del tiempo el habitar, la movilidad social y espacial a que se han enfrentado sus residentes. Por otra parte, el contexto urbano en Juárez marca distintos mosaicos sociales, históricos, demográficos y culturales que nos hacen pensar en una ciudad de fragmentos, islas urbanas. Esto en relación con viviendas destinadas a sectores de altos ingresos, ubicadas en toda la ciudad pero con tendencia a predominar en el norte, y las de integración ecológica, que se incluyen en el sector 3 del mapa 1, en contraste con el fuerte impulso en la zona sur y oriente para los de ingresos medios y bajos.

Otros escenarios que se han detectado en la tríada movilidad social, entorno construido y espacio público se incluyen en el mapa 2, cuya distribución espacial lo representan tres categorías básicas: condominio, fraccionamiento y fraccionamiento con condominio, asentamientos urbanos que combinan tanto la movilidad social de tipo horizontal como la vertical. Los grupos de medios y altos ingresos convierten dichos asentamientos en su fortaleza para buscar, por un lado, ascensos a niveles sociales de 
convivencia homogéneos, y por otro, habitar en espacios donde la seguridad, exclusividad y distinción permean nuevos focos de interacción individual y colectiva.

En el mapa 2 se incluyen las tipologías marcadas con el número 1, que representan al condominio, cuya ubicación es muy puntual en las zonas surponiente y oriente, con enclaves habitacionales que se mezclan con el resto de las viviendas. Por su parte, el número 2 integra al fraccionamiento (abierto y cerrado) donde la concentración tiende en su mayor parte hacia la parte nororiente de la ciudad, pero también con gran dispersión en cuanto a tamaño en las áreas del suroriente. Hacia el Poniente, el mapa presenta pequeños conjuntos habitacionales. Los fraccionamientos con condominio forman islas en la zona suroriente, particularizando vialidades principales y zonas concretas (marcadas con el número 3 en el mapa). Este tipo de categorías habitacionales se relaciona con la movilidad vertical en su mayor parte, ya que es el nivel de ingreso el que determina la selección del lugar donde se habitará por parte de sus residentes y por tanto es lo que decide qué nivel en su escala económica y social ocupa: ascenso o descenso, lo cual, entonces, puede producir nuevos cambios en la movilidad que experimenten los residentes de las zonas que se anotan en el mapa 2.

Otro elemento a reflexionar en esta construcción de escenarios donde se produce la movilidad social de tipo vertical, es el lugar y el entorno donde se sitúan cada uno de ellos. Por ejemplo, en el caso del condominio, los grupos que habitan aquí manifiestan sus percepciones y experiencias. Por otro lado, las categorías de fraccionamientos pueden ser abiertos o cerrados, y ya con esta categoría estamos hablando de un tipo de movilidad social específica que se relaciona con la vivienda (tamaño, ubicación y tipo de construcción). Puede ser el tipo de fraccionamiento de interés social o medio, una cualidad más para identificar la movilidad social que se genera en cada uno. 
Mapa 2. Distribución de vivienda por tipo de desarrollo

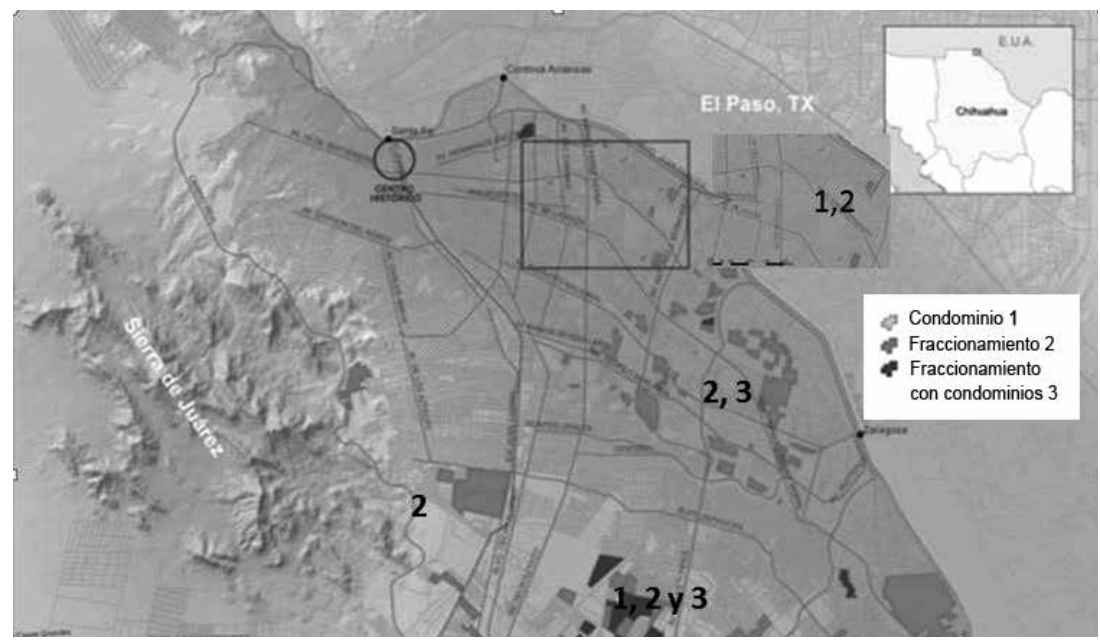

Fuente: Elvira Maycotte et al. (2007). Estudio del impacto de la política de vivienda en Ciudad Juárez. Consejo Nacional de Vivienda (Conavi).

La distribución de la tipología de estos escenarios urbanos se aprecia en el mapa 2 y se relaciona con los datos que se incluyen en la tabla 2, en relación con la intervención del sector gubernamental o privado que se encargan de construir la ciudad con esta tipología de fraccionamientos. Por ejemplo, en el 2002, de los 13 conjuntos construidos, 11 corresponden a la categoría de fraccionamiento y 2 a fraccionamiento con condominio, y de ellos, 3 fueron edificados por el sector público y 10 por el privado. Del 2006 al 2008 hay un proceso evolutivo en la construcción de los conjuntos habitacionales que se edifican en el sur, oriente y norte de la ciudad.

Un proceso interesante es la medida en que en estos años se considera que hay una bonanza en la ciudad, en los cuales la estructura urbana se configuraba como potencial núcleo de desarrollo al suroriente. Al respecto, enfatiza Maycotte (2011: 180) que la política de vivienda ha tenido una profunda incidencia en los patrones de crecimiento de la ciudad. Adoptada por las empresas privadas para desarrollar sus predios en forma individual y poco coordinada, sin una visión integral que conduzca a la articulación de las actividades, los usos, trazas y la equidad en la 
dotación de servicios e infraestructura. O bien, como lo explican Fuentes y Peña (2011: 32), que el norponiente y surponiente (sector 4 del mapa1), se caracterizan por recibir a los sectores de bajos ingresos que no pueden acceder a los mecanismos formales de compra de vivienda, por lo que experimentan un proceso de autoconstrucción.

Tabla 2. Desarrollos habitacionales en Ciudad Juárez, 2002-2010

\begin{tabular}{|c|c|c|c|}
\hline Año & Total & Tipo & Acción \\
\hline \multirow[t]{2}{*}{2002} & 13 & 11 fraccionamientos & 3 públicos \\
\hline & & 2 fraccionamientos-condominio & 10 privados \\
\hline \multirow[t]{3}{*}{2003} & 10 & 4 fraccionamientos & 2 públicos \\
\hline & & 4 fraccionamiento-condominio & 8 privados \\
\hline & & 2 condominios & \\
\hline \multirow[t]{2}{*}{2004} & 7 & 7 fraccionamientos & 6 públicos \\
\hline & & & 1 privado \\
\hline \multirow[t]{2}{*}{2005} & 9 & 9 fraccionamientos & 8 privados \\
\hline & & & 1 público \\
\hline \multirow[t]{2}{*}{2006} & 13 & 13 fraccionamientos & 8 públicos \\
\hline & & & 5 privados \\
\hline \multirow[t]{2}{*}{2007} & 24 & 24 fraccionamientos & 20 privados \\
\hline & & & 4 públicos \\
\hline \multirow[t]{2}{*}{2008} & 16 & 14 fraccionamientos & 13 privados \\
\hline & & 2 condominios & 3 públicos \\
\hline \multirow[t]{2}{*}{2009} & 10 & 8 fraccionamientos & 8 privados \\
\hline & & 2 condominios & 2 públicos \\
\hline \multirow[t]{2}{*}{2010} & 7 & 6 fraccionamientos & 7 privados \\
\hline & & 1 condominio & \\
\hline
\end{tabular}

Fuente: Elaboración del equipo de trabajo "Proyecto movilidad social" con base en información de Desarrollo Urbano de Ciudad Juárez

El mapa 3 presenta la prospectiva de los desarrollos habitacionales establecidos en Ciudad Juárez durante los años 1981 al 2010, para mostrar el crecimiento poblacional y urbano de esta 
localidad fronteriza que se relaciona con los procesos de movilidad social, entorno construido y espacio público. Como se aprecia en esta cartografía, el periodo marcado con los años 1991 a 1999 y 2000 al 20010, las áreas del norponiente, parte del poniente, el sur y sur oriente son los ejes rectores en los movimientos poblacionales hacia estas zonas con distintos modelos de vivienda, desde aquellas de autoconstrucción, de interés social y fraccionamientos cerrados, condominios y asentamientos irregulares, entre otras formas. El mapa 3 muestra este crecimiento y por tanto aparece un tipo de movilidad horizontal específica que es de carácter interno, es decir, los residentes se mueven en busca de una vivienda propia, por tanto, el fenómeno social tiene nuevas orientaciones y en cambio el tipo vertical mantiene ritmos constantes en esas situaciones.

El suroriente, como se aprecia en esta cartografía, representaba para el gobierno municipal un eje motriz en el desarrollo urbano de Juárez. Se planeaba que esta zona tuviera un despegue en todos los sentidos: social, económico, cultural y urbanístico. Por ejemplo, en la tabla 3 se muestran los datos del 2000 al 2008 en cuanto a población, superficie, densidad e incremento por hectáreas, destacando el 2000 en relación con el incremento en la superficie por hectáreas; al igual que el 2008, son años que coinciden con la distribución de la mancha urbana al suroriente que se muestra en el mapa 3.

Tabla 3. Datos demográficos de Ciudad Juárez. 2000 al 2008

\begin{tabular}{cccccc}
\hline Año & Población & Superficie & Densidad & Incremento & No de has. \\
\hline & & $($ Has. $)$ & (hab/ha.) & (Has.) & Anuales \\
\hline 2000 & 1208498 & 20553.00 & 57.46 & 5189.26 & 1037.85 \\
\hline 2005 & 1301452 & 22684.77 & 57.37 & 2131.77 & 426.35 \\
\hline 2008 & 1371494 & 30052.89 & 42.00 & 7368.12 & 2456.04 \\
\hline
\end{tabular}

Fuente: IMIP (2010). Plan de Desarrollo Urbano Municipal. Gobierno de Ciudad Juárez 
Mapa 3. Desarrollo habitacional en Ciudad Juárez 1981 a 2010.

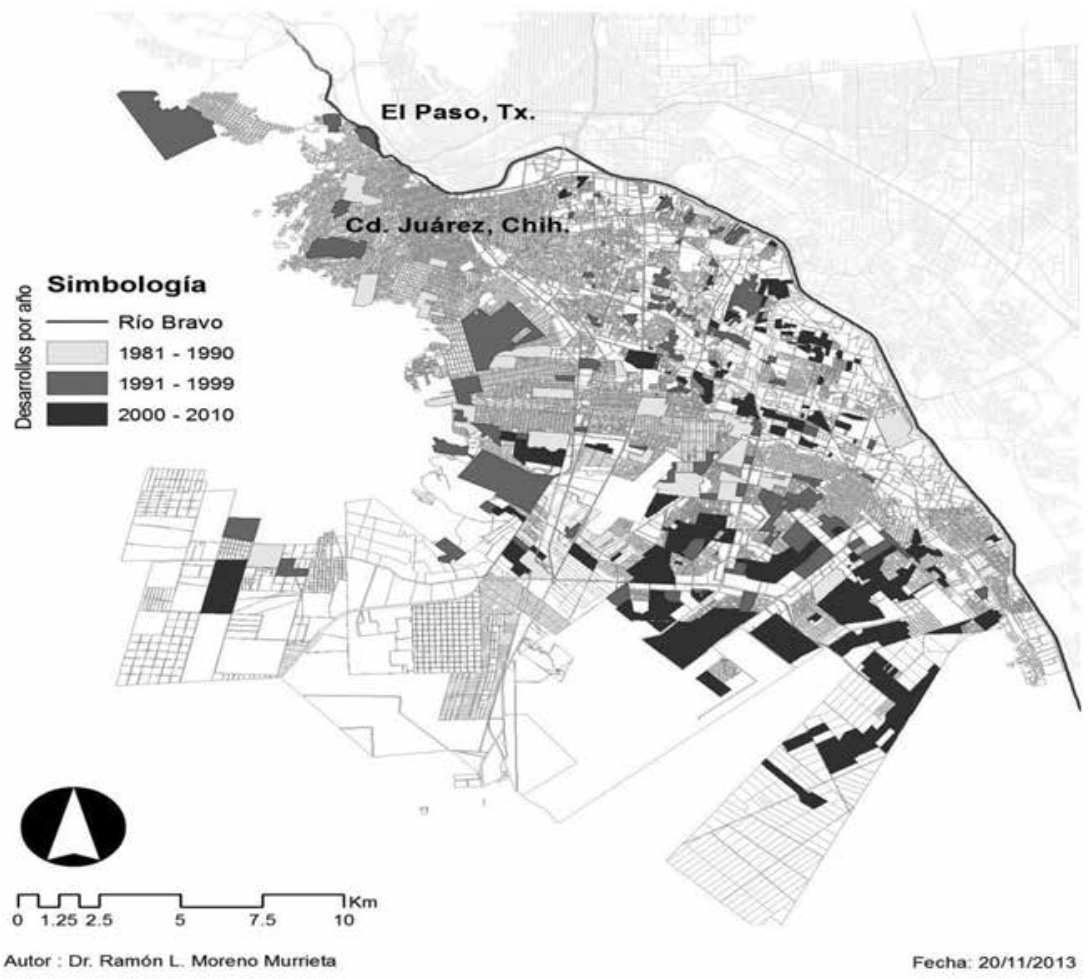

Fuente: Elaboración de Ramón L. Moreno M. con base en información de IMIP (2011). Relación de colonias en Ciudad Juárez

Estos escenarios dan pistas para visualizar nuevos procesos en la configuración urbana de los espacios públicos y el entorno construido que se ha diseñado en distintos tiempos en la historia de Juárez como ciudad, sobre todo en relación con las categorías de la movilidad social ya citadas en la tabla 2 y que se vinculan con los mapas 1, 2 y 3 para continuar con las expresiones, experiencias y símbolos de los residentes propietarios que se abordarán en la siguiente sección. 


\section{EXPERIENCIAS DE MOVILIDAD SOCIAL EN CIUDAD JUÁREZ}

Este apartado explica alguna de las cualidades que se obtuvieron en el trabajo de campo a residentes propietarios de vivienda de interés social en las que se aplicaron cuestionarios, registros fotográficos y cartografías para indicar el lugar donde se ubica la vivienda de estos actores. Se tomó una muestra para el análisis de los resultados de este cuestionario relacionados con el artículo.

Para identificar los elementos relacionados en este apartado, la información se clasifica en dos categorías principales: a) el contexto urbano, tipo de vivienda y fotografía del lugar; b) la experiencia de los actores o propietarios.

a) Contexto urbano, tipo de vivienda y lugar

En esta categoría se trata de identificar el lugar y el tipo de vivienda en donde se localizan los actores que señalaron ser propietarios, lo cual permite construir los mecanismos que se realizaron en la construcción de entornos urbanos heterogéneos, tanto en la vivienda como en el espacio público y el entorno que se fue diseñando en cada uno de estos asentamientos urbanos. Para propósitos de este estudio y en relación con la información del proyecto "Medición de indicadores de movilidad social en residentes propietarios en viviendas de interés social”, coordinado por Elvira Maycotte Pansza, realizado durante 2001-2014, se construyó el mapa 4 para ubicar 68 colonias y fraccionamientos de interés social en las distintas zonas que constituyen Ciudad Juárez: Norte, Sur, Poniente, Nororiente y Suroriente, con grupos sociales y económicos distintos que nos pudieran ayudar a comprender la movilidad social que se estaba gestando en la localidad y cuyos entornos se describen de la siguiente manera:

- Zona norte: próxima a la línea fronteriza, y resultó en el estudio un solo tipo de fraccionamiento.

- Zona sur: territorio plano y con diversidad en los modelos de vivienda.

- Zona poniente: territorio con superficie montañosa y también con modelos diferentes en cuanto a la tipología de vivienda. 
- Zona suroriente: diversidad en cuanto a población, espacio público con intervenciones urbanas, viviendas de interés social, fraccionamientos abiertos y cerrados, entre otros aspectos.

- Zona nororiente: un territorio diverso en cuando a medio físico, población media, alta y baja en algunos sectores, fraccionamientos cerrados para grupos económicos bajos, medios y altos.

Mapa 4. Ubicación de colonias y fraccionamientos donde se aplicó el cuestionario de movilidad social.
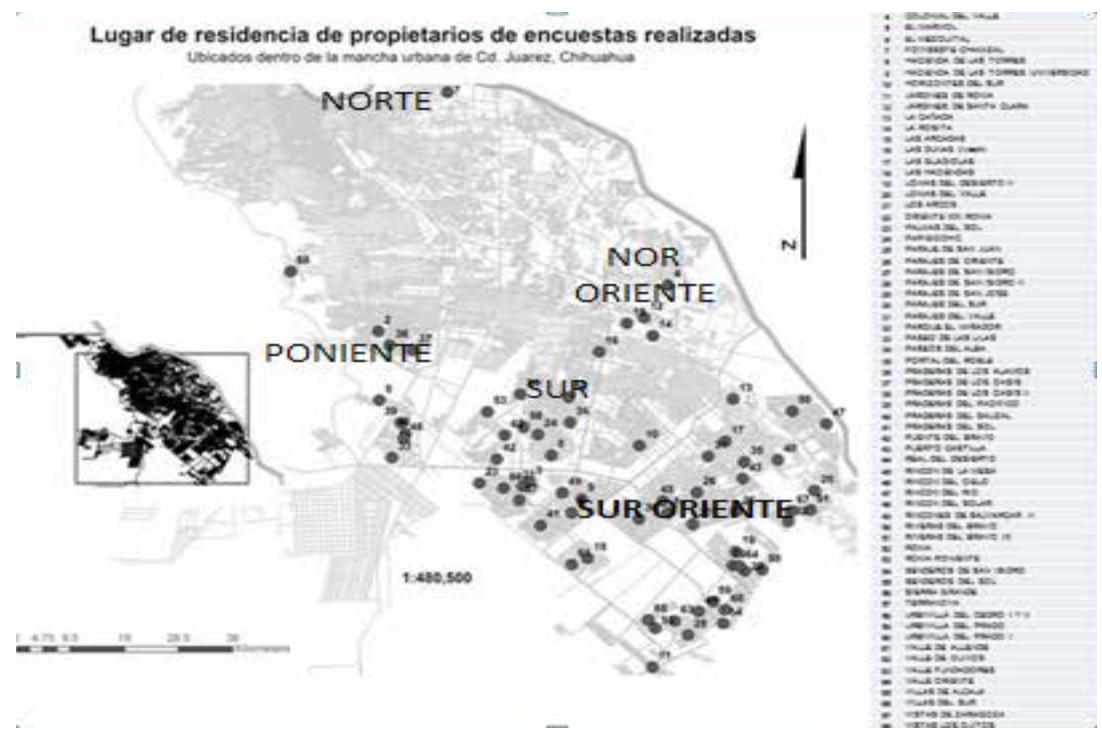

Fuente: Elaboración de Jonathan Olguín Arredondo (2014) con base en información del proyecto "Medición de indicadores de movilidad social en residentes propietarios en viviendas de interés social”, coordinado por Elvira Maycotte Pansza.

La tabla 4 complementa la información por zonas que se muestran en el mapa 3. Ahí se puede observar la cantidad de colonias y fraccionamientos donde se aplicó el cuestionario para conocer la opinión, las percepciones, vivencias en la ciudad y otros indicadores para conocer y describir la movilidad social y espacial que se ha generado en Ciudad Juárez. 
Tabla 4. Número de colonias y fraccionamientos encuestados por zona

\begin{tabular}{cc}
\hline Ubicación & Cantidad \\
\hline Norte & 1 \\
\hline Sur & 5 \\
\hline Poniente & 8 \\
\hline Nororiente & 5 \\
\hline Suroriente & 49 \\
\hline Total & 68 \\
\hline
\end{tabular}

Fuente: Elaboración propia con base en información del proyecto: Medición de indicadores de movilidad social en residentes propietarios en viviendas de interés social, coordinado por Elvira Maycotte Pansza.

Con respecto a las fotografías de las colonias y fraccionamientos donde residen los propietarios, se tomó una muestra correspondiente a 2002 con los casos de Mezquital y Haciendas de las Torres, incluidas en la figura 3, y que se ubican en las zonas sur y suroriente respectivamente (señaladas en el mapa 4 con los números 6 y 8). El entorno urbano es de un mosaico distinto en ambos casos. En el primero se nota una mayor amplitud en la vivienda y su infraestructura, y en el segundo aparecen significados y emblemas del lenguaje que se describen en el fraccionamiento. Estos lugares corresponden a 2002 como año fundacional. 
Figura 3. Fraccionamientos urbanos de Ciudad Juárez en 2002

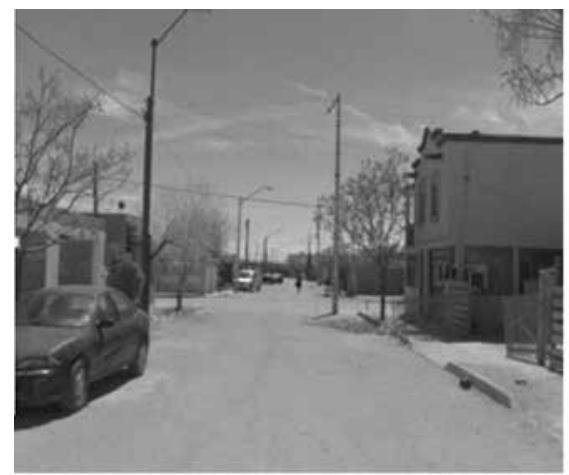

El Mezquital

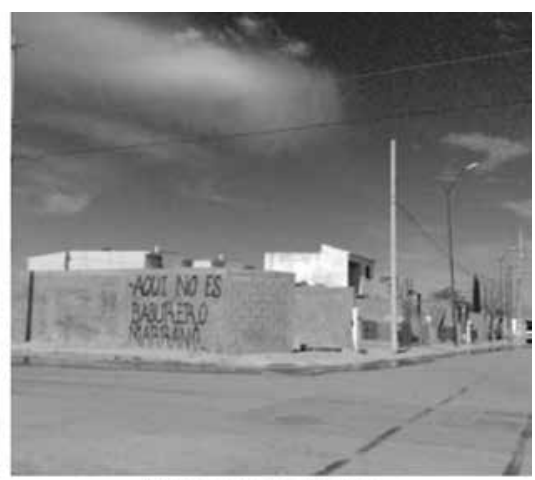

Hacienda las Torres

Fuente: Archivos del proyecto "Medición de indicadores de movilidad social en residentes propietarios en viviendas de interés social”, coordinado por Elvira Maycotte Pansza.

En el caso de Los Arcos y Rincones de Salvárcar II ( figura 4), el entorno urbano que identifica a estos dos fraccionamientos ubicados en la zona suroriente y fundados en 2004, parecieran mostrar que sus proyectos se dirigían a clases medias, por los prototipos de vivienda que se diseñaron en ellos. Los residentes, si bien es cierto que en el primero no habitaron en forma total el fraccionamiento, algunos de sus propietarios decidieron permanecer en él, mientras que en el segundo, Rincones de Salvárcar II, hay un espacio mayormente habitado por sus residentes. La ubicación en el mapa 4 de estos conjuntos es establecida con los números 21 y 49 , respectivamente. 
Figura 4. Conjuntos habitacionales en Ciudad Juárez, 2004

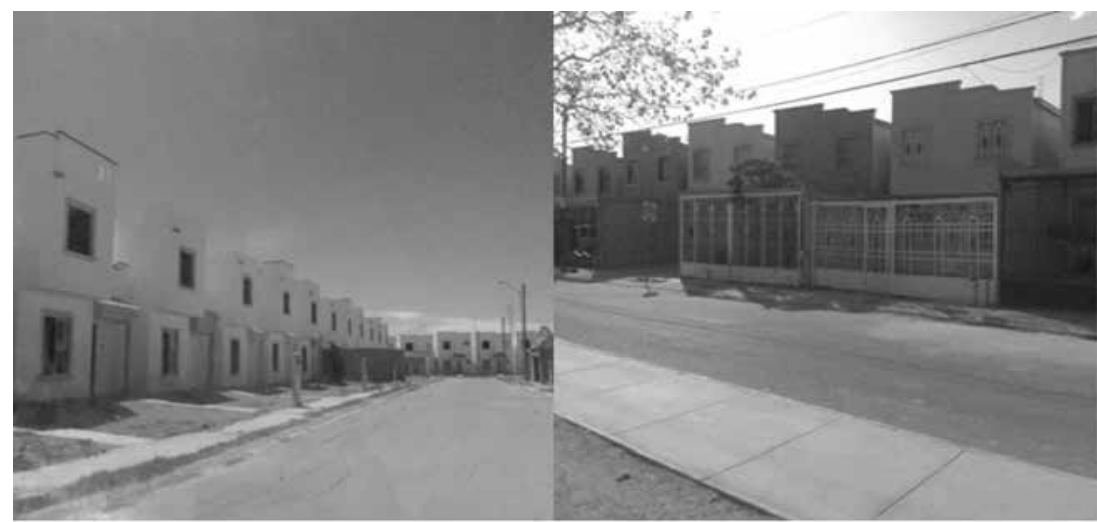

LOS ARCOS

RINCONES DE SALVARCAR ॥

Fuente: Archivos del proyecto "Medición de indicadores de movilidad social en residentes propietarios en viviendas de interés social”, coordinado por Elvira Maycotte Pansza.

Por su parte, Parajes de San Juan y Valle de Allende, ubicados en la zona suroriente de Juárez, representan otros ejemplos del prototipo de vivienda que se diseñó para grupos económicos de bajos y medios ingresos. El objetivo principal de estos conjuntos de vivienda que se establecieron en la ciudad en 2006 era arraigar y establecer a sus residentes en su vivienda. El entorno que se estableció para ellos se incluye en la figura 5, donde uno de los hechos principales de este año lo representa el abandono de vivienda, lo cual impactaría no solo en el espacio interno de estos fraccionamientos, sino que a nivel de ciudad, este repercutiría en las condiciones de vida de la población de Juárez. 
Figura 5. Conjuntos habitacionales en Ciudad Juárez, 2006

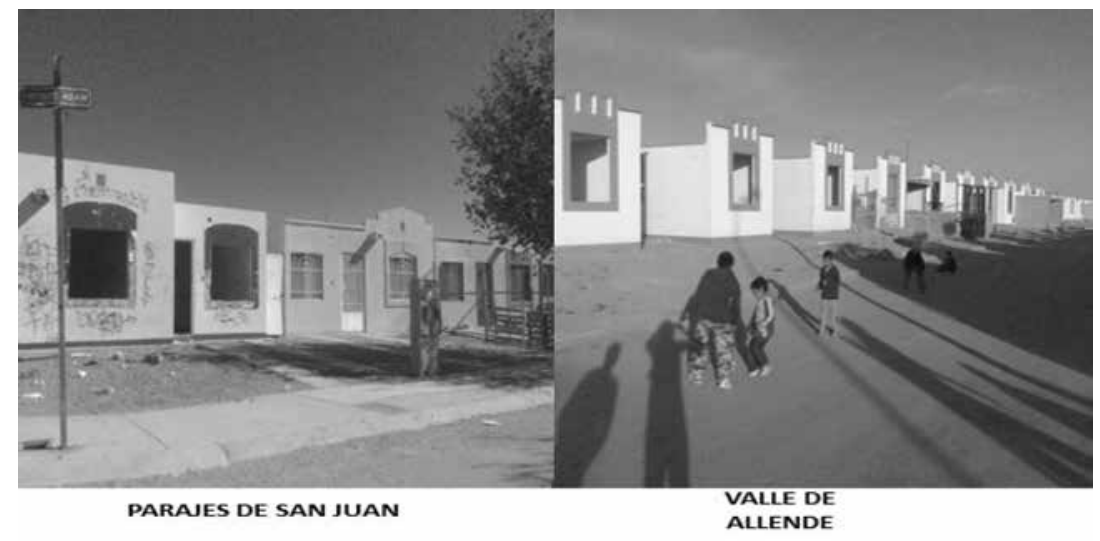

Fuente: Archivos del proyecto "Medición de indicadores de movilidad social en residentes propietarios en viviendas de interés social”, coordinado por Elvira Maycotte Pansza.

b) Experiencia de los actores o propietarios

Esta sección permite identificar los actores propietarios a quienes se les aplicó el cuestionario para conocer sus experiencias, definiciones y percepciones de la realidad de su habitar y en relación con sus expectativas de obtener una vivienda propia, y si esto ayudó o no a mejorar su movilidad social.

\section{Datos demográficos de los actores}

\section{Población por género}

En relación con sus cualidades demográficas, la figura 6 establece su condición por género, resultando que el propietario es en su mayor parte el esposo en un $56.1 \%$, en contraparte con el $27.9 \%$ correspondiente a la esposa. Una tercera categoría, "ambos son propietarios", obtiene un 8.2 \%, y el término "otro" corresponde al $7.9 \%$ del total de casos. Esto indica la importancia fundamental del hombre como jefe de familia, quien resulta ser el proveedor para satisfacer las necesidades elementales del grupo y por tanto para conseguir los bienes necesarios. 
El papel de la mujer, en este caso de la esposa, cumple un rol significativo en este proceso de identificar a los actores e identificar la movilidad social, ya que al asumir condición de trabajadora forma parte de la población económicamente activa, que se dispone a colaborar en la satisfacción de las necesidades fundamentales en el grupo.

La categoría "ambos son propietarios", si bien es cierto no es un porcentaje elevado en contraste con los dos anteriores, es un indicador que representa una ilustración importante en la configuración del ascenso y descenso en la estructura colectiva del grupo para mejorar sus condiciones de vida en la ciudad.

Figura 6. Composición demográfica de los actores propietarios de vivienda de interés social en Ciudad Juárez

\begin{tabular}{|c|c|c|}
\hline & Frecuencia & \%Valico \\
\hline Esposo & 213 & 56.1 \\
\hline Esposa & 106 & 27.9 \\
\hline Ambos & 31 & 8.2 \\
\hline$\overline{O \text { Otro }}$ & 30 & 7.9 \\
\hline
\end{tabular}

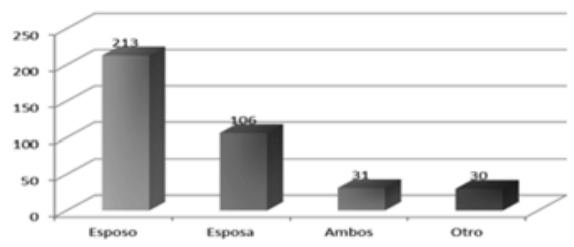

Fuente: Archivos del proyecto "Medición de indicadores de movilidad social en residentes propietarios en viviendas de interés social", coordinado por Elvira Maycotte Pansza.

\section{Población según edad}

En cuanto al grupo etario de los propietarios de vivienda de interés social en Ciudad Juárez, las condiciones de los encuestados tienden situarse entre los grupos de 30 a 34 y 35 a 39 años. Eso representa una población joven que adquiere su patrimonio propio en forma independiente, lo que nos lleva a pensar las condiciones económicas en las que se ven insertos en su vida laboral en Ciudad Juárez. Otros grupos etarios que resultaron sobresalientes en la encuesta aplicada durante 2011-2014, son los de 25 a 29 años; en cuarto término, los de 40 a 44, como se muestra en la información de la figura 7.

La información anterior permite visualizar las características demográficas de estos actores que decidieron adquirir su vivienda y con ello mejorar sus condiciones de vida, pero sobre todo la 
trayectoria de los actores de estos grupos de edad, que influye en sus decisiones, formas de ver la vida y sobre todo garantizar la obtención de mejores ingresos y con ello escalar nuevos peldaños en su jerarquía, no solo económica, sino también social y cultural.

Figura 7. Grupo etario de los residentes propietarios de vivienda de interés social en Ciudad Juárez

\begin{tabular}{|c|c|c|}
\hline & Frecuencia & $\%$ Valido \\
\hline 15 a 19 aก๊os & 2 & .5 \\
\hline 20 a 24 aก̃os & $\overline{20}$ & $\overline{5.3}$ \\
\hline 25 a 29 aกี่os & $\overline{60}$ & $\overline{15.8}$ \\
\hline 30 a 34 aกัos & 79 & 20.8 \\
\hline 35 a 39 aก๊os & 70 & 18.5 \\
\hline 40 a 44 aก̃os & 59 & 15.6 \\
\hline 45 a 49 aก๊os & 41 & 10.8 \\
\hline 50 a 54 aก๊os & 22 & 5.8 \\
\hline 55 a 59 aก̃os & $\overline{12}$ & $\overline{3.2}$ \\
\hline 60 a 64 aก̃os & $\frac{8}{8}$ & 2.1 \\
\hline 65 aก̃os o más & 6 & 1.6 \\
\hline
\end{tabular}

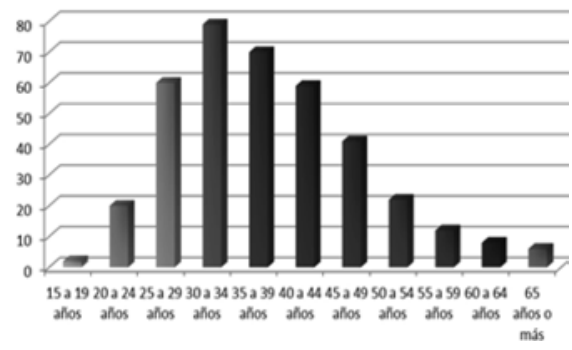

Fuente: Archivos del proyecto "Medición de indicadores de movilidad social en residentes propietarios en viviendas de interés social", coordinado por Elvira Maycotte Pansza.

\section{USOS Y PRÁCTICAS EN RELACIÓN A LA MOVILIDAD SOCIAL}

En este apartado se describen algunas condiciones que resultaron del cuestionario aplicado a los residentes propietarios, usando para ello: a) el tiempo de residir en Ciudad Juárez como indicador que nos permite conocer el arraigo y el desplazamiento que tienen los mismos dentro de la ciudad; b) vivienda actual, sobre la cual expresan opiniones y definiciones de la misma; y c) una comparación con la vivienda de sus padres, para visualizar estas experiencias.

a) Tiempo de residencia en Ciudad Juárez

La figura 8 presenta esta información, en la que se observa que el mayor porcentaje concierne a población nativa de Juárez. Es, entonces, un indicador que registra un arraigo a esta ciudad fronteriza (30.3\%) en la cual se manifiesta la permanencia definitiva de la población que se ha asentado en la misma durante los últimos años y además permitiría un tipo de movilidad espacial de tipo local donde el ascenso al estatus estaría determinado apro- 
ximadamente por el grado de escolaridad y los deseos de ser independientes de sus padres. La segunda categoría representativa de este apartado son los residentes que tienen de 10 a 14 años habitando esta ciudad, seguidos por los que tienen de 15 a 19 años, y en cuarto término se consideran los que tienen de 20 a 24 años. La gráfica de esta figura 8 indica el comportamiento de residencia de los habitantes de Ciudad Juárez.

Figura 8. Tiempos de residencia

de los residentes propietarios en Ciudad Juárez
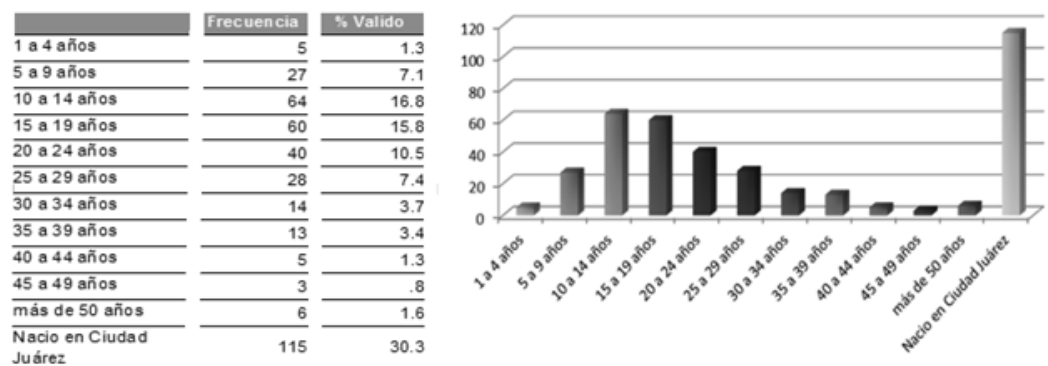

Fuente: Archivos del proyecto "Medición de indicadores de movilidad social en residentes propietarios en viviendas de interés social”, coordinado por Elvira Maycotte Pansza.

b) Vivienda actual

Elemento que nos permite conocer las respuestas de los residentes propietarios en cuanto al tiempo que tienen de ocupar su vivienda actual. Esta información se convierte en relevante por la cantidad de tiempo que llevan en esa vivienda. Por ejemplo, la figura 9 señala esos datos y se explica que la mayor parte de ellos (201 casos), tienen entre 5 y 9 años; son seguidos por los residentes que afirmaron que su tiempo de ocupar su casa es entre $1 \mathrm{a}$ 4 años; y en tercer término están los que tienen de 10 a 14 años (77 casos). Estos datos, como se observa en la figura 8, concentran en estas tres categorías el arraigo a su casa. Este resultado puede indicar la posibilidad de una movilidad social de reciente inicio y sobre todo confirmar una tendencia a crear un desplazamiento espacial de carácter definitivo. 
Figura 9. Tiempo de ocupar su vivienda los residentes propietarios en Ciudad Juárez

\begin{tabular}{|c|c|c|}
\hline & Frecuencia & $\%$ Valido \\
\hline 1 a 4 años & 88 & 23.2 \\
\hline 5 a 9 aก̃os & 201 & 52.9 \\
\hline 10 a 14 años & 77 & 20.3 \\
\hline 15 a 19 años & $\overline{2}$ & .5 \\
\hline 25 a 29 años & $\overline{1}$ & .3 \\
\hline 30 a 34 años & 1 & .3 \\
\hline 35 a 39 años & 1 & 3 \\
\hline Menos de 1 año & $\overline{9}$ & 2.4 \\
\hline
\end{tabular}

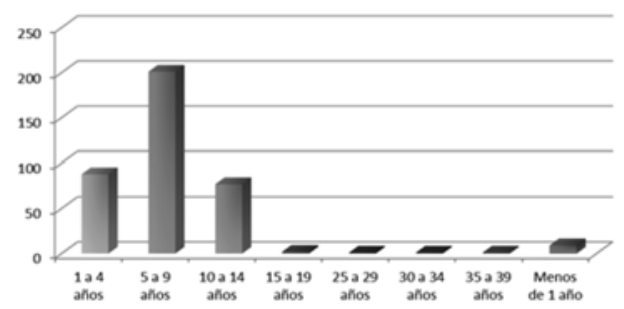

Fuente: Archivos del proyecto "Medición de indicadores de movilidad social en residentes propietarios en viviendas de interés social”, coordinado por Elvira Maycotte Pansza.

La figura 10 muestra las respuestas de aquellos residentes propietarios que tuvieron una vivienda anterior antes de la actual, con lo que proceden a vislumbrar la construcción del patrimonio propio, pero que estuvo representado por el hogar de sus padres. Esta figura permite explicar un proceso importante en la movilidad social de estos residentes. Hay un desplazamiento que se gesta en esta información.

Figura 10. Vivienda propia antes de la actual
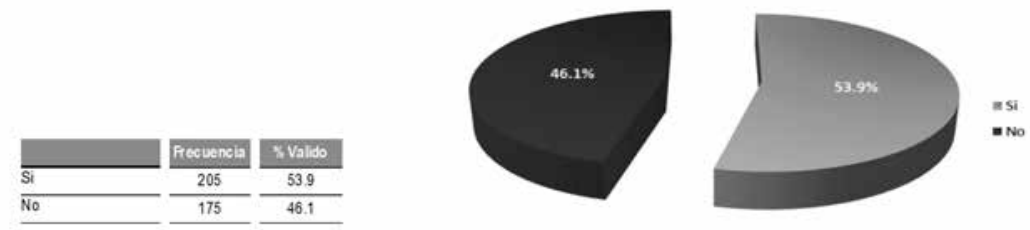

Fuente: Archivos del proyecto "Medición de indicadores de movilidad social en residentes propietarios en viviendas de interés social", coordinado por Elvira Maycotte Pansza.

c) Vivienda propia y su relación con la de los padres

Este apartado incluye la información referente a la posición que generaron los residentes propietarios en relación con la de sus padres, y la evaluación que tuvieron en cuanto a su habitar, el tamaño y las condiciones en general de las mismas. Los datos muestran algunas reflexiones interesantes, sobre todo en la per- 
cepción de los encuestados en relación con la vivienda actual, la anterior y la de los padres, que se muestran en la figura 11.

Figura 11. Vivienda actual, anterior y la de sus padres
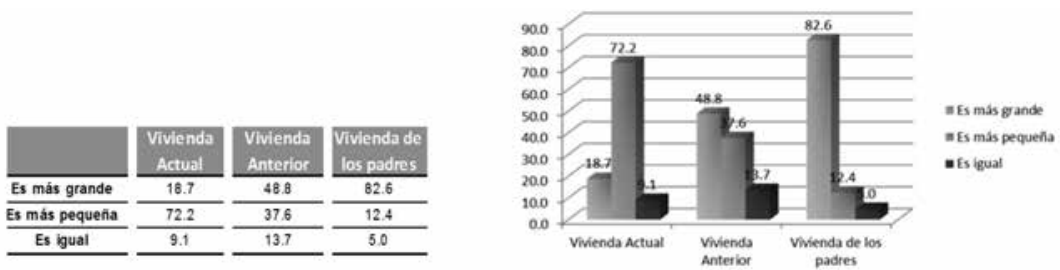

Fuente: Archivos del proyecto "Medición de indicadores de movilidad social en residentes propietarios en viviendas de interés social", coordinado por Elvira Maycotte Pansza.

Como se observa en la figura 11, tanto en la tabla como en la gráfica, la evaluación en cuanto al tamaño de la casa muestra mayor porcentaje en la de los padres; en segundo término, si se habitó en otra vivienda y, finalmente, la actual tiene una valoración baja. Esto indica que no es del agrado suficiente la casa donde se vive cotidianamente, ya que es más pequeña que la de sus padres e inclusive que la vivienda donde se vivió anteriormente.

Con respecto al tamaño de las habitaciones de la vivienda, hay datos relevantes de los encuestados en relación con sus percepciones sobre donde habitaron antes, donde lo hacen ahora y en donde vivieron con sus padres. Sin duda alguna en la figura 12, la casa donde habitaron con sus padres tiene una preferencia sobre dónde se vivió antes y en la que se vive actualmente. En esta información solo tiene representación significativa la vivienda actual porque tiene habitaciones pequeñas. Estas ideas hablan de un descontento con respecto a los nuevos modelos de vivienda que se habitan y si se consideran como ejemplos algunas de ellas que se describen en las figuras 3, 4 y 5. 
Figura 12. Tamaño de habitaciones en la vivienda actual, la anterior y la de sus padres
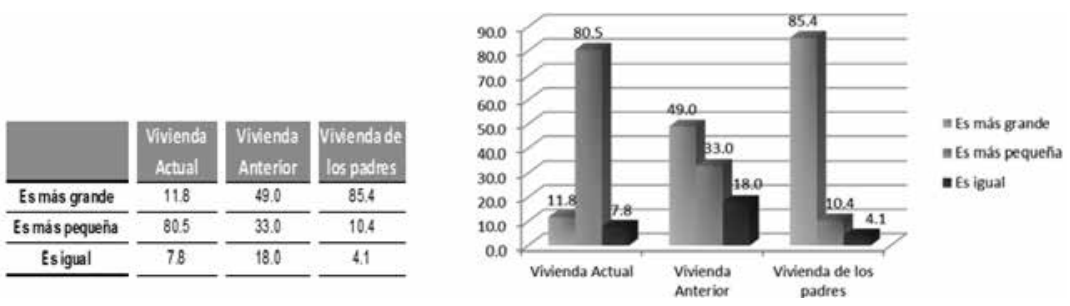

Fuente: Archivos del proyecto "Medición de indicadores de movilidad social en residentes propietarios en viviendas de interés social”, coordinado por Elvira Maycotte Pansza.

\section{REFLEXIONES FINALES}

La movilidad social en sectores populares, bajos y medios en Ciudad Juárez, aunado a las condiciones generales de la ciudad, modificó en forma sustantiva los anhelos de buscar un proyecto de vida que les permitiera ir ascendiendo en forma secuencial y lógica por los senderos de las mejoras de sus necesidades. También las tipologías migratorias influyen en este ambiente que en algunas zonas se fue creando por medio de los estereotipos que el lugar y el medio social en donde se asentaron les crearon.

Además, se crearon situaciones contextuales que unieron a los residentes para permanecer y defender su territorio. La idea del patrimonio propio, aunque no les convence mucho, sí tiene un alto valor de arraigo a sus lugares; se les creó una conciencia de pertenencia a pesar de las condiciones que les otorgó el entorno. Incluso el espacio público, que en un principio les parecía feo y desagradable, fue transformando su imagen en la medida que se incorporaron al lugar elegido.

A partir de las diferencias espaciales, en Ciudad Juárez se hace necesario realizar propuestas de revitalización urbana en vivienda, vialidades, parques, servicios y equipamientos urbanos, sobre todo porque se han visto en este estudio las condiciones territoriales en las que se ha enfocado la expansión urbana de Juárez. Es menester contar con propuestas que surjan en beneficio de las condiciones generales de vida que imperan en la ciudad. 
Otro elemento que se debe agregar en esta reflexión final es considerar la organización comunitaria, sobre todo en adaptar las nuevas condiciones de su vivienda actual a aquellas que obtuvieron en donde se vivió antes o con las de sus padres, para fomentar un sentimiento de arraigo. Sin embargo, las condiciones del tamaño de la vivienda son un obstáculo para lograr este hecho.

Por otro lado, la movilidad social tiene estrecha relación con el entorno que construye el hombre porque se conecta directamente con el espacio público que se edifica al interior de colonias y fraccionamientos; en algunos casos, ello se manifiesta en la construcción de valores propios y determinantes en la vida cotidiana de los residentes que habitan la zona suroriente de Ciudad Juárez. En este sentido, las demandas de la población deben ser atendidas también a nivel de propuestas de revitalización de los espacios sociales, donde se generan los procesos de socialización e interacción.

En efecto, la posible interacción de los medios donde se habitó antes, el actual y el de los padres, que forman parte de este análisis de la movilidad social en relación con la construcción socioespacial, permite mejorar el medio ambiente físico con el social. La vinculación de ambos será parte de un eje de convivencia con el presente y el pasado, que se retoma de manera crucial en la cotidianidad de los residentes propietarios.

\section{BIBLIOGRAFÍA}

Berruecos, L. (2012). Una aproximación interdisciplinaria a los conceptos de espacio y territorio, en M. Reyes y A. López (coords.), Explorando territorios: una visión desde las ciencias sociales (pp. 49-80). México: Universidad Autónoma Metropolitana.

Brenna, J. (2012). Espacio y territorio: una visión sociológica, en M. Reyes y A. López (coords.), Explorando territorios: una visión desde las ciencias sociales (pp. 81-106). México: Universidad Autónoma Metropolitana.

Campos, G. (2012). Las dimensiones constitutivas del espacio público urbano: hacia una perspectiva cultural, en M. Reyes y A. López (coords.) 
Explorando territorios: una visión desde las ciencias sociales (pp. 161-188). México: Universidad Autónoma Metropolitana.

Fuentes, C. y S. Peña (2011). Espacio público y género. Hacia un marco teórico, metodológico y contextual, en C. Fuentes, L. Cervera, J. Monárrez y S. Peña (coords.) Espacio público y género en Ciudad Juárez, Chihuahua (pp. 27-62). El Colegio de la Frontera Norte, Universidad Autónoma de Ciudad Juárez.

Giddens, A. (2009). Sociología. Barcelona: Alianza Editorial.

Maycotte, E. (2011). La participación del espacio público en la cotidianidad de los residentes de vivienda social en Ciudad Juárez, Chihuahua: una observación a los patrones de uso durante el periodo de 2005-2009, en C. Fuentes, L. Cervera, J. Monárrez y S. Peña (coords.) Espacio público y género en Ciudad Juárez Chihuahua (pp. 175-212). El Colegio de la Frontera Norte, Universidad Autónoma de Ciudad Juárez.

Maycotte, E. (2013). Reporte de investigación del proyecto “Determinación de indicadores, diseño de metodología de los residentes propietarios para medir la movilidad social”. Ciudad Juárez: Universidad Autónoma de Ciudad Juárez.

Maycotte, E. (2014). Movilidad social de residentes propietarios de viviendas de interés social en Ciudad Juárez: una aproximación a su medición en términos de la vivienda y su contexto urbano, en E. Maycotte (coord.), Colección Desafíos de la planificación ante la creciente complejidad urbana, vol. 1, 69-83. Instituto de Arquitectura, Diseño y Arte, UACJ.

Moreno, R. (2014). El habitar, espacio urbano y construcción de los imaginarios en Ciudad Juárez, en J. Chávez (coord.), Colección Desafíos de la planificación ante la creciente complejidad urbana, vol. 2, 224. Instituto de Arquitectura, Diseño y Arte, UACJ.

Rodríguez, M. (2011). Espacio público, centralidades y experiencias de género. Desafíos actuales para "hacer ciudad" en Ciudad Juárez, Chihuahua, en C. Fuentes, L. Cervera, J. Monárrez y S. Peña (coords.), Espacio público y género en Ciudad Juárez Chihuahua (pp. 63-90). Ciudad Juárez: El Colegio de la Frontera Norte, Universidad Autónoma de Ciudad Juárez.

\section{Material cartográfico}

Instituto Municipal de Investigación y Planeación (2010). Plan de Desarrollo Urbano en Ciudad Juárez. H. Ayuntamiento de Ciudad Juárez. 
Elvira Maycotte, et al. (2007). Estudio del impacto de la política de vivienda en Ciudad Juárez. Consejo Nacional de Vivienda (Conavi).

Jonathan Olguín Arredondo. Diseño de cartografía de localización de fraccionamientos y colonias. Universidad Autónoma de Ciudad Juárez.

\section{Apoyo fotográfico}

Ramón Leopoldo Moreno Murrieta 